\title{
Real-Time Modelling and Optimisation for Water and Energy Efficient Surface Irrigation
}

\author{
Kanya L. Khatri ${ }^{1}$, Ashfaque A. Memon ${ }^{2}$, Yasin Shaikh ${ }^{3}$, Agha F. H. Pathan ${ }^{2}$, \\ Sadiq A. Shah ${ }^{1}$, Kanwal K. Pinjani ${ }^{4}$, Rabia Soomro ${ }^{1}$, Rod Smith ${ }^{5}$, Zaheer Almani ${ }^{2}$ \\ ${ }^{1}$ Department of Civil Engineering, Mehran University of E \& T, Khairpur Campus, Pakistan \\ ${ }^{2}$ Department of Civil Engineering, Mehran University of E \& T, Jamshoro, Pakistan \\ ${ }^{3}$ Department of Industrial Engineering, Mehran University of E \& T, Jamshoro, Pakistan \\ ${ }^{4}$ Water Resources Division, National Engineering Services, Lahore, Pakistan \\ ${ }^{5}$ Faculty of Engineering and Surveying Queensland, USQ Toowoomba, Australia \\ Email: rajaln@yahoo.com, kanwalpinjani@hotmail.com, ssssadiqalishah@gmail.com
}

Received April 15, 2013; revised May 16, 2013; accepted June 17, 2013

Copyright @ 2013 Kanya L. Khatri et al. This is an open access article distributed under the Creative Commons Attribution License, which permits unrestricted use, distribution, and reproduction in any medium, provided the original work is properly cited.

\begin{abstract}
The viability and sustainability of crop production is currently threatened by increasing water scarcity. Water scarcity problems can be addressed through improved water productivity and the options usually presumed in this context are efficient water use and conversion of surface irrigation to pressurised systems. By replacing furrow irrigation with drip or centre pivot systems, the water efficiency can be improved by up to $30 \%$ to $45 \%$. However, the installation and application of pumps and pipes, and the associated fuels needed for these alternatives increase energy consumption. A balance between the improvement in water use and the potential increase in energy consumption is required. When surface water is used, pressurised irrigation systems increase energy consumption substantially, by between $65 \%$ to $75 \%$, and produce greenhouse gas emissions around 1.75 times higher than that of gravity based irrigation systems so their use should be carefully planned keeping in view adverse impact of carbon emissions on the environment and threat of increasing energy prices. With gravity-fed surface irrigation methods, the energy consumption is assumed to be negligible. This study has shown that a novel real-time infiltration model REIP has enabled implementation of real-time optimisation and gravity fed surface irrigation with real-time optimisation has potential to bring significant improvements in irrigation performance along with substantial water savings of $2.92 \mathrm{ML} / \mathrm{ha}$ which is equivalent to that given by pressurised systems. The real-time optimisation and control thus offers a modern, environment friendly and water efficient system with close to zero increase in energy consumption and minimal greenhouse gas emissions.
\end{abstract}

Keywords: Water Scarcity; Real-Time Optimisation; Furrow Irrigation; Carbon Emissions; REIP

\section{Introduction}

Worldwide as well as in Australia, irrigated agriculture is the largest water user, and there is pressure on irrigators to improve water use efficiency as other sectors compete for water. One way of improving water use efficiency is to replace gravity-fed irrigation systems such as border check and furrow, with more efficient pressurised centre pivot and drip systems [1,2] because these conversions can offer a significant reduction in water application at the field scale, up to $220 \mathrm{~mm}$ equivalent to $2.2 \mathrm{ML} / \mathrm{ha}$ [3]. Current government policy in Australia encourages the modernisation of irrigation systems, with the aim of generating water savings of over 2500 GL per year within the Murray-Darling Basin, where 85\% of Australia's irrigation takes place. There are limited details regarding the specific methods for modernisation; however, one option usually assumed for modernisation will be to convert to pressurised irrigation systems in order to generate significant water savings.

Irrigation is a primary consumer of energy on farms [4], so any changes to the irrigation method used can be expected to change on-farm energy consumption. Direct energy inputs are primarily the fuel sources used to operate farm machinery and pumps, while indirect energy inputs refer to energy that is used to produce equipment and other goods and services that are used on-farm [5]. Between $23 \%$ and $48 \%$ of direct energy used for crop production is used for on-farm pumping [6,7]. Where pressurised groundwater extraction is used, there is always more energy required for pumping and delivery to 
the field. The energy required for pumping depends on crop water requirement, total dynamic head, flow rate and system efficiency [8]. Crops with a higher water requirement result in a larger amount of water being pumped and increase energy consumption that will increase carbon dioxide and or greenhouse gas (GHG) emissions and thus adding to environmental degradation. If a gravity-fed irrigation method is used in conjunction with a surface water source, the energy required to transport and apply water to the field is negligible [9] and there will be minimal or zero increase in energy consumption and minimal carbon dioxide $\left(\mathrm{CO}_{2}\right)$ emissions.

Amongst gravity-fed irrigation methods, furrow irrigation is the most commonly used method for irrigating crops and pastures in northern Australia and around the world, the energy consumption in surface water resourced regions is assumed to be negligible, but this method is generally perceived to be low efficient method of irrigating crops, bound by inherent characteristics and traditional practices to wasting much of the water applied [10]. In fact it is not the fault of method but indeed it is the lack of proper management and a limited capability to predict the soil infiltration characteristic.

The performance of surface irrigation is a function of the field design, infiltration characteristic of the soil, and the irrigation management practice. However, the complexity of the interactions makes it difficult for irrigators to identify optimal design or management practices. The infiltration characteristic of the soil is the most crucial factor affecting the performance of surface irrigation [10] and both spatial and temporal variations in the infiltration characteristic are a major physical constraint to achieving higher irrigation application efficiencies. While well designed and managed surface irrigation systems may have application efficiencies of up to $90 \%$ [11], many commercial systems have been found to be operating with significantly lower and highly variable efficiencies. Previous research in the sugar industry found application efficiencies for individual irrigations ranging from 14\% to $90 \%$ and with seasonal efficiencies commonly between $31 \%$ and $62 \%$. Application efficiencies in the cotton industry have been shown of similar range and magnitude [12].

A real-time control system has the potential to overcome the infiltration issues and significant improvements in irrigation performance up to 30 to $40 \%$ are possible with optimization of individual irrigation events. A study was undertaken [13] to identify the potential improvement in irrigation performance (application efficiency, storage efficiency and distribution uniformity) achievable through real time control strategies. The management variables flow rate and application time required to maximize the application efficiency were calculated for each individual irrigation throughout the season. When these management parameters were optimized using SIRMOD model for each irrigation throughout the season to simulate real-time control of individual irrigations, the average application efficiency increased significantly to $93 \%$ with a storage efficiency of $90 \%$, without any significant difference in the distribution uniformity.

The term real time control applied to the analysis of field parameters in surface irrigation means that irrigation information is collected, studied and processed during the irrigation. The results obtained are used to modify the management variables for the same irrigation. The necessary information can be obtained from advance data or field run-off. A computer model called SIRTOM (surface irrigation real time optimization model) was developed [14] to estimate the infiltration parameters in real time from advance data. The model used a one-dimensional optimization technique to obtain the parameters $(k)$ and $\left(f_{o}\right)$ of the Kostiakov-Lewis equation. The parameter (a) was determined separately by the two-point method [15]. Camacho developed the IPE [16] model for management and control of furrow irrigation in real time. The objective was to find the infiltration parameters that simulate water advance best fitted to the field measured data. The model estimated the parameters only $(k)$ and $a$ of the Kostiakov-Lewis equation, where as the parameter $\left(f_{o}\right)$ was to be initially calculated by using indirect methods. The major drawback of these models is that they are data intensive and difficult to operate. The IPE model also requires the final infiltration parameter $\left(f_{o}\right)$ to be measured separately which is time consuming and difficult to measure accurately. The high data requirement is a major hindrance to the implementation of any form of real-time control [17]. To over-come this problem a new model to prediction of infiltration in real-time (REIP) that uses a model infiltration curve and a scaling technique was developed by Khatri and Smith [10]. The method requires minimum field data, inflow and only one advance point measured around the mid length of the furrow. The method has potential for use in real time irrigation optimisation and control.

This study is a part of research project being conducted for development of a practical surface irrigation real-time control system at University of Southern Queensland Australia. In the present paper, the improvements in surface irrigation performance through real-time optimisation and control are assessed and the water savings quantified. The savings in energy consumption, from that required by a change to pressurised irrigation systems, are estimated. It will be evident that Real-time optimisation and control of surface irrigation when applied in conjunction with automation offers a modern environment friendly, labour and water efficient system with close to zero energy consumption and minimal GHG emissions. 


\section{Data Analysis}

\subsection{Description of the Real-Time Optimisation and Control System}

The real-time optimisation and control system involves:

- measurement or estimation of the inflow to each furrow or group of furrows,

- measurement of the advance at one point approximately mid way down the furrow,

- estimation of the infiltration characteristic for the furrow or group of furrows using the scaling technique of Khatri and Smith [20],

- simulation of the irrigation and optimization to determine the optimum time to cut off the inflow to achieve improved performance and efficient irrigation application.

The actual measurement, simulation and control would preferably be automated but could be undertaken manually with very little capital investment on the part of the farmer. A necessary precursor to application of the system is the determination of the shape of the infiltration characteristic (model infiltration curve) for the particular field or soil type. This is best done from a comprehensive evaluation of one or more furrows from the field, involving measurements of the inflow, advance and where possible runoff, with the infiltration curve being determined using a model such as IPARM [18]. The preferred (constant) furrow inflow rate is also determined at this stage although it may be altered over time as experience with operation of the system is accumulated.

Any infiltration equation can be used however for consistency with available simulation models the present study employs the Kostiakov-Lewis equation:

$$
I=k \tau^{a}+f_{o} \tau
$$

where $I$ is the cumulative infiltration $\left(\mathrm{m}^{3} / \mathrm{m}\right), a, k$, and $f_{o}$ are the fitted parameters, and $\tau$ is the infiltration time (min).

The cumulative infiltration curve calculated from these parameters is the model infiltration curve. Subsequently the model infiltration parameters can be used to estimate (by scaling) the cumulative infiltration curves for the whole field, and other irrigation events, using only one advance point for each of the remaining furrows or for each subsequent irrigation event.

In this method a scaling factor $(F)$ is formulated for each furrow or event from a re-arrangement of the volume balance model (as used by McClymont and Smith [22]):

$$
F=\frac{Q_{o} t-\sigma_{y} A_{o} x}{\sigma_{z} k t^{a} x+\frac{f_{o} t x}{1+r}}
$$

where: $Q_{o}$ is the inflow rate for the corresponding furrow $\left(\mathrm{m}^{3} / \mathrm{min}\right), A_{o}$ is the cross-sectional area of the flow at U/S end of furrow $\left(\mathrm{m}^{2}\right)$ (determined by any appropriate method), $t$ (min) is the time for the advance to reach the distance $x(\mathrm{~m})$ for the corresponding furrow. $a, k, f_{o}$ are the infiltration parameters of the model furrow, $\sigma_{y}$ is a surface shape factor taken to be a constant (0.77), $\sigma_{\mathrm{z}}$ is the sub-surface shape factor for the model furrow, defined as:

$$
\sigma_{z}=\frac{a+r(1-a)+1}{(1+a)(1+r)}
$$

where $r$ is the exponent from power curve advance function $x=p(t)^{r}$ for the model curve of the furrow.

This scaling factor $(F)$ is then applied in conjunction with the Kostiakov-Lewis infiltration model to scale the infiltration curves for the whole field as follows:

$$
I_{s}=F\left(k \tau^{a}+f_{o} \tau\right)
$$

where: $I_{s}$ is the scaled infiltration $\left(\mathrm{m}^{3} / \mathrm{m}\right), a, k, f_{o}$ are the infiltration parameters of the model furrow.

The scaling factor $F$ as given by Equation (2) can be defined as the ratio between the infiltrated volume as calculated by a volume balance in the trial furrow at $t_{50}$ and the infiltrated volume as calculated by the parameters for the model furrow. The application of the factor (Equation (3)) follows from this definition and assumes each part ( $k$ and $f_{o}$ ) of the infiltration function be scaled in the same proportion.

For the real-time optimisation and control the infiltration estimates are required in sufficient time to allow selection and application of optimum times to cut-off while the irrigation event is under way. To achieve this, the advance times $\left(t_{50}\right)$ taken at the mid-point down the furrow/field $\left(x_{50}\right)$ are used in Equation (2).

\subsection{Irrigation Performance and Infiltration Data}

Two fields one with maize, field C1; and other one with cotton field C2, were selected for study and analysis with a total of 46 furrow irrigation events conducted by growers using their usual practices, 24 furrow irrigation events for field C1 and 22 furrow irrigation events for field C2. These fields were selected from the different commercial farms across the crop growing areas of Central Queensland for which volume of irrigation water use and irrigation advance data have been collected. The basis for selection was the relatively large number of events for each field.

Data collected for each irrigation event included:

- furrow inflow and outflow rates;

- irrigation advance (advance times for various points along the length of furrow including the time for the advance to reach the end of the furrow);

- physical characteristics of the furrow (length, slope, 
cross section shape).

The flow rate and irrigation advance were measured using the IRRIMATE ${ }^{\mathrm{TM}}$ suite of tools developed by the National Centre for Irrigation in Agriculture, as described by Dalton [19]. The infiltration parameters for each furrow/event for the three fields, estimated by the method of Khatri and Smith, have been used in simulation and optimisation to demonstrate the achievable gains in water productivity through improved irrigation performance.

\subsection{Simulation and Optimisation SIRMOD (Surface Irrigation Simulation, Evaluation and Design)}

To evaluate the real-time optimization control, simulations were performed for the two fields using the infiltration parameters in the simulation model SIRMOD [20]. These SIRMOD simulations were used to evaluate the irrigation performance (application efficiency $E a$, requirement or storage efficiency $E r$, and distribution uniformity $D U$ ) of the current farm irrigations and assess the possible potential gains in performance improvement and volume of water savings achieved through real time control; and comparison of this improvement (Water saving) to that achieved when systems are converted to centre pivot and or drip irrigation.

SIRMOD is a software package designed to simulate the hydraulics of surface irrigation at the furrow scale, and to optimize the irrigation system parameters to maximize application efficiency. The input data required for the simulation component of the model include field length, slope, infiltration characteristics, target application depth, flow rate, Manning $\mathrm{n}$ and furrow geometry. The model output includes a detailed advance-recession trajectory, distribution of infiltrated water, volume balance, runoff hydrograph, water distribution uniformity, and the water application and requirement efficiencies. The ability of the SIRMOD to evaluate the irrigation performance of furrows and borders has been well documented for example by McClymont [21].

The three performance measures used in the evaluation have their usual meanings.

Application efficiency $E a$ is defined as the ratio of volume of water stored in the root zone during irrigation to volume of water delivered in the field during that irrigation and usually expressed as a percentage.

Requirement (or storage) efficiency $\mathrm{Er}$ is a measure of the adequacy of the irrigation. It is defined as the ratio of water stored in the root zone during irrigation to water required (the deficit) in the root zone prior to irrigation. Uniformity describes the spatial distribution of water over the field. The performance measure used in this paper, distribution uniformity $D U$, is defined as the average of the lowest $25 \%$ of infiltrated depths of water divided by the average infiltrated depth of water over the whole field.

Modelling and evaluation strategies:

To perform the simulations, three (3) irrigation strategies were framed to evaluate the real time optimisation control and to demonstrate the achievable gains in irrigation performance.

The modelling strategies adopted are:

Strategy 1: Prediction of the current farm irrigation simulated using the infiltration parameters (REIP $a, k, f_{o}$ ), actual inflow $\left(Q_{o}\right)$ and actual cut-off time $\left(t_{c o}\right)$ as recorded under usual farm practices.

Strategy 2: Optimisation of the current farm irrigation. In this case each irrigation event was optimized by using the REIP infiltration parameters and varying the inflow and cut-off time to obtain maximum application efficiency $(E a)$. This strategy also determines the best overall flow rate.

Strategy 3: A simple practical real-time control strategy in which the REIP infiltration parameters were used with a fixed inflow rate while varying/optimizing only the cut-off time to achieve the best irrigation and maximum water saving.

\section{Energy Consumption in Irrigation}

With increasing demand being placed on water resources the efficient use of water resources is inevitable to achieve increased food production. Increasing water scarcity and malfunctioning irrigation systems, now threaten the viability and sustainability of crop production. Water scarcity problems can be addressed through improved water productivity [22] and the option usually supposed to be in this context is application of pressurised irrigation systems.

The use of pressurised irrigation systems requires substantial capital investments. In addition, installation and application of pumps and pipes, and the associated fuels and oils needed to run them emit significant quantities of greenhouse gases. The studies [23,24] show that amount of GHG emissions from pumping irrigation system is around 1.47 times higher than that of canal irrigation systems. It has been shown that around $3.8 \mathrm{kgCO}_{2} \mathrm{e}$ and $2.68 \mathrm{kgCO}_{2} \mathrm{e}$ of $\mathrm{GHG}$ emissions are produced respectively per litre of diesel and oil consumption and have adverse impact on environment. In case of replacing furrow irrigation with drip, centre pivot or sprinkler systems, the water efficiency can be improved up to $30 \%-45 \%$ but it does increase energy consumption along with GHG emissions.

Energy consumption in irrigated agriculture results primarily from pumping requirements. This is well illustrated in a recent case study in Australia by Jackson [25]. They considered five irrigation farms and range of crops in each of two areas. The first was the Coleambally Irrigation Area in southern NSW, where farms are supplied 
with surface water by gravity and the second a groundwater area in South Australia. The water use and energy consumption by the current (inefficient) surface irrigation systems were compared with the reduced water use but greatly increased energy consumption that would occur if the surface systems were converted to centre pivot and drip irrigation. They concluded that in surface water regions investments should target improvements to the existing surface systems. However in the groundwater region they recommended adoption of pressurised systems. In neither case did they attempt to quantify the water or energy savings that would occur from optimised surface irrigation systems.

Under this research study average water consumption under surface irrigation application, real-time application, and when converted to centre pivot and drip irrigation application have been computed for a field corn crop to assess the corresponding water saving (ML/ha) and energy consumption (MJ/ha) under each irrigation application system. In this case the water source is a surface gravity supply and the energy used in the surface irrigation cases is entirely for the cultural operations of land preparation, sowing, fertiliser, herbicides and harvesting; and are based on calculation methods as used in other studies [26-28]. The increased energy consumptions for the centre pivot and drip systems are a direct result of the pumping required to give the desired operating pressures.

\section{Results and Discussion}

\subsection{Irrigation Performance}

The summary of simulated irrigation performance results obtained for the model strategies are shown in Tables 1 and 2 for fields C1 and C2 respectively. The results obtained under each of the model strategies are discussed below.

\section{Strategy 1 (Current irrigation-farm management):}

From the summary of simulation results for field C1 (Table 1) it is evident that the overall mean irrigation performance (application efficiency and storage efficiency) of the actual irrigations (strategy 1) was substandard, with mean application efficiency $E a$ of $52.4 \%$ and storage efficiency $\operatorname{Er}$ 95.4\%. However, application efficiencies were shown to be highly variable from 40 to 93\%. Similarly in case of field C2 the application efficiencies showed considerable variation from 26 to $57 \%$, but this field showed poorer performance (Table 2) with an overall mean application efficiency of $42.3 \%$ and storage efficiency of $97.6 \%$.

Strategy 2 (Advanced Real-time Management):

In this case each irrigation event was optimized by varying inflow $\left(Q_{o}\right)$ and cut-off time $\left(t_{c o}\right)$ to suit individual soil conditions and furrow characteristics. As expected an excellent performance was obtained for most
Table 1. Summary of furrow irrigation performance under different strategies for field C1.

\begin{tabular}{cccc}
\hline $\begin{array}{c}\text { Management } \\
\text { practice }\end{array}$ & $\begin{array}{c}\text { Application } \\
\text { efficiency \% }\end{array}$ & $\begin{array}{c}\text { Storage } \\
\text { efficiency \% }\end{array}$ & $\begin{array}{c}\text { Distribution } \\
\text { uniformity \% }\end{array}$ \\
\hline $\begin{array}{c}\text { Current farmer } \\
\text { Management practice } \\
\text { Advanced Real-time } \\
\text { optimisation and control }\end{array}$ & 52.4 & 95.4 & 92.6 \\
$\begin{array}{c}\text { Simple Real-time } \\
\text { optimisation and control }\end{array}$ & 82.5 & 92.3 & 93.4 \\
\hline
\end{tabular}

Table 2. Summary of furrow irrigation performance under different strategies for field $\mathrm{C} 2$.

\begin{tabular}{cccc}
\hline $\begin{array}{c}\text { Management } \\
\text { practice }\end{array}$ & $\begin{array}{c}\text { Application } \\
\text { efficiency \% }\end{array}$ & $\begin{array}{c}\text { Storage } \\
\text { efficiency \% }\end{array}$ & $\begin{array}{c}\text { Distribution } \\
\text { uniformity \% }\end{array}$ \\
\hline $\begin{array}{c}\text { Current farmer } \\
\text { management practice } \\
\text { Advanced Real-time }\end{array}$ & 42.3 & 97.6 & 92.3 \\
optimisation and control & 88.5 & 90.5 & 93.5 \\
$\begin{array}{c}\text { Simple Real-time } \\
\text { optimisation and control }\end{array}$ & 85.2 & 88.6 & 86.8 \\
\hline
\end{tabular}

events. The mean over all irrigation performance ( $E a$ and $E r$ ) obtained for all of the irrigation events for field C1 was above $92 \%$ and for field C2 the Ea was above $88.5 \%$ and $\operatorname{Er}$ 92.5\% as shown in Tables $\mathbf{1}$ and 2. This strategy involves the application of more advanced irrigation management practices. The overall best flow rate of $6 \mathrm{l} / \mathrm{s}$ as observed under this strategy was selected for use in strategy 3.

Strategy 3 (Simple Real-time optimisation and control):

From Tables $\mathbf{1}$ and $\mathbf{2}$ it is evident that the simple real time optimisation and control strategy (3) using the REIP infiltration parameters predicts improved performance ( $E a$ and $E r$ ) for both fields. For field C1 the means of the performance measures are $E a$ 88.2\% and $E r$ 90.4\%, with mean $E a$ of $85.2 \%$ and $E r 88.6 \%$ for field C2. The outcomes from the real time control strategy obtained indicate that simple real-time optimisation and control for achieving high efficiency in irrigated agriculture is feasible and significant gains in irrigation performance are possible from field optimisation system.

\subsection{Water Savings from Real-Time Optimisation and Control}

The performance simulation results (Tables $\mathbf{1}$ and 2) show there is considerable opportunity to improve the irrigation performance obtained under current farm practices (strategy 1). When the real time control (strategy 3) was applied the overall mean irrigation performance was improved for both fields. A highly significant improvement in irrigation performance was noted in case of field C2, with application efficiency increasing from $42.3 \%$ to 
85.2\% as shown in Table 2, along with acceptable uniformity and storage efficiency. It is evident from these results that the simple real-time control system does have potential to bring significant gains in irrigation performance, with the additional benefit of reducing the volume of water applied per irrigation and deep drainage volumes, thus reducing the potential for environmental harm.

Table 3 presents the total volumes of water applied to the 46 furrows at fields C1 and C2 under current farm management and real-time control. It can be seen from the table that the volume of water applied to the 46 furrows at fields C1 and C2 was reduced from $4036 \mathrm{~m}^{3}$ under usual farm management to $2246 \mathrm{~m}^{3}$ under real-time control. This indicates the substantial potential savings of $1590 \mathrm{~m}^{3}$ (1.59 ML) of volume of water per irrigation (over $3.27 \mathrm{ha}$ ), which is a significant loss of water to the grower. For Queensland cotton growers usually applying 6 irrigations annually this represents annual water saving of $2.92 \mathrm{ML} / \mathrm{ha}$ that can be used beneficially to grow further crop area, clearly indicating the substantial benefits that are achievable in the irrigation industry by implementing simple real-time field optimisation and control.

\subsection{Energy Consumption in Irrigation}

The summary of water savings and energy consumption in irrigation under different irrigation application systems is shown in Table 4. It is evident that when real-time optimisation control was implemented over current surface irrigation the water savings to tune of $2.92 \mathrm{ML} / \mathrm{ha}$ were achieved without increase in energy consumption which reveals significant water savings with no increase in carbon emissions, hence real-time field optimisation and control proved to be water efficient and environment friendly.

The table further reflects that when current surface irrigation system was converted to centre pivot and drip irrigation, a further meager water saving of 0.1 and 0.3 $\mathrm{ML} / \mathrm{ha}$ was achieved, in comparison to real-time control, along with highly significant rise in energy consumption to the tune of $175 \%$ and $165 \%$ respectively for centre pivot and drip irrigation application.

A balance between the improvement in water use and

Table 3. Volume of water saving achieved under furrow irrigation for Field C1 and C2.

\begin{tabular}{cccc}
\hline $\begin{array}{c}\text { Field } \\
\text { Specification }\end{array}$ & $\begin{array}{c}\text { Water Applied } \\
\text { under farm } \\
\text { management }\left(\mathrm{m}^{3}\right)\end{array}$ & $\begin{array}{c}\text { Water applied } \\
\text { under real-time } \\
\text { control }\left(\mathrm{m}^{3}\right)\end{array}$ & $\begin{array}{c}\text { Water savings } \\
\text { due to real-time } \\
\text { control }\left(\mathrm{m}^{3}\right)\end{array}$ \\
\hline Field C1 & 2258 & 1433 & 825 \\
Field C2 & 1778 & 1013 & 765 \\
Total & 4036 & 2246 & 1590 \\
\hline
\end{tabular}

Table 4. Water savings and energy consumption under different irrigation systems.

\begin{tabular}{ccccc}
\hline Irrigation system & $\begin{array}{c}\text { Water } \\
\text { applied } \\
\text { (ML/ha) }\end{array}$ & $\begin{array}{c}\text { Water } \\
\text { savings } \\
\text { (ML/ha) }\end{array}$ & $\begin{array}{c}\text { Energy } \\
\text { consumption } \\
\text { (MJ/ha) }\end{array}$ & $\begin{array}{c}\text { Increase in } \\
\text { energy } \\
\text { consumption } \\
\text { (MJ/ha) }\end{array}$ \\
\hline $\begin{array}{c}\text { Current farm } \\
\text { surface irrigation } \\
\text { Real-time }\end{array}$ & 7.52 & - & 9720 & - \\
$\begin{array}{c}\text { Optimized } \\
\text { surface irrigation }\end{array}$ & 4.60 & 2.92 & 9720 & 0 \\
$\begin{array}{c}\text { Centre } \\
\text { pivot irrigation } \\
\text { application } \\
\begin{array}{c}\text { Drip irrigation } \\
\text { application }\end{array}\end{array}$ & 4.51 & 3.01 & 17040 & 7320 \\
\hline
\end{tabular}

the significant increase in energy consumption is required. When surface water is used, pressurised systems increase energy consumption substantially high, so their use should be planned keeping in view adverse impact of increased carbon emissions on global warming and threat of increasing energy prices that may cause farmers to pay more and save less per hectare, in addition to environment degradation. Energy consumption is increased more by installing centre pivot systems than drip systems, because these systems generally require a higher operating pressure and are less efficient, resulting in more water being pumped and hence increasing energy consumption.

\section{Conclusions}

Under this study, the gains achievable in irrigation performance from real-time optimisation and control of furrow irrigation that varies only the time to cut-off, have been assessed. To evaluate the gains from the system, the SIRMOD model was used to simulate the irrigation performance for two different fields, under different irrigation modelling strategies using actual farm irrigation data. The increase in energy consumption that required for a change to pressurised irrigation has been computed. It is concluded that:

Real-time optimisation and control is an efficient irrigation management tool and has the potential to bring significant improvement in irrigation performance over that achieved under current farmer management, and the substantial reductions in the total volume of water applied per irrigation achievable.

More importantly, as the system is gravity fed based, improved performance is achieved without increase in energy consumption along with zero increase in greenhouse gas emissions. Thus real-time optimisation and control offers a modern, environment friendly, water and energy efficient system.

Conversion of surface irrigation to modern pressurised 
systems, as an alternative for improved performance, causes substantial increase in energy consumption so their use should be carefully planned, keeping in view the threat of increasing energy prices and adverse impact of carbon emissions on environmental degradation.

\section{REFERENCES}

[1] E. Playan and L. Mateos, "Modernization and Optimization of Irrigation Systems to Increase Water Productivity," Agricultural Water Management, Vol. 80, No. 1-3, 2006, pp. 100-116. doi:10.1016/j.agwat.2005.07.007

[2] A. J. B. Zehnder, H. Yang and R. Schertenlieb, "Water Issues: The Need for Action at Different Levels," Aquatic Sciences, Vol. 65, No. 1, 2003, pp. 1-20. doi:10.1007/s000270300000

[3] Pratt Water, “The Business of Saving Water," The Report of the Murrumbidgee Valley Water Efficiency Feasibility Project, Campbellfield, Victoria, 2004.

[4] R. L. Naylor, "Energy and Resource Constraints on Intensive Agricultural Production," Annual Review of Energy and the Environment, Vol. 21, 1996, pp. 99-123. doi:10.1146/annurev.energy.21.1.99

[5] D. Pimentel, "Energy Inputs in Production Agriculture," In: R. C. Fluck, Ed., Energy in Farm Production, Elsevier, Amsterdam, 1992. doi:10.1016/B978-0-444-88681-1.50007-7

[6] A. W. Hodges, G. D. Lynne, M. Rahmani and C. F. Casey, "Adoption of Energy and Water-Conserving Irrigation Technologies in Florida," University of Florida Report, Florida, 1994.

[7] H. Singh, D. Mishra and N. M. Nahar, "Energy Use Pattern in Production Agriculture of a Typical Village in Arid Zone, India, Part I,” Energy Conversion and Management, Vol. 43, No. 16, 2002 pp. 2275-2286. doi:10.1016/S0196-8904(01)00161-3

[8] R. Lal, “Carbon Emission from Farm Operations,” Environment International, Vol. 30, No. 7, 2004, pp. 981-990. doi:10.1016/j.envint.2004.03.005

[9] B. A. Stout, "Handbook of Energy for World Agriculture,” Elsevier Science Publishers Ltd., Essex, 1990. doi:10.1007/978-94-009-0745-4

[10] K. L. Khatri and R. J. Smith, "Real-Time Prediction of Soil Infiltration Characteristics for Management of Furrow Irrigation,” Irrigation Science, Vol. 25, No. 1, 2006, pp. 33-43. doi:10.1007/s00271-006-0032-1

[11] D. Anthony, "On-Farm Water Productivity, Current and Potential: Options, Outcomes, Costs,” Irrigation Australia, Vol. 10, No. 1, 1995, pp. 20-23.

[12] R. J. Smith, S. R. Raine and J. Minkovich, "Irrigation Application Efficiency and Deep Drainage Potential under Surface Irrigated Cotton,” Agricultural Water Management, Vol. 71, No. 2, 2005, pp. 117-130. doi:10.1016/j.agwat.2004.07.008

[13] S. R. Raine, D. J. McClymont and R. J. Smith, “The Development of Guidelines for Surface Irrigation in Areas with Variable Infiltration,” Proceedings of Australian So- ciety of Sugarcane Technologists, Vol. 1, No. 1, 1997, pp. 293-301.

[14] C. A. V. Azevedo, G. P. Merkley and W. R. Walker, "Surface Irrigation Real-Time Optimization Model (SIRTOM)," ASAE Conference on Computers in Agriculture, Cancun, 12-14 October 1996.

[15] R. L. Elliott and W. R. Walker, "Field Evaluation of Furrow Infiltration and Advance Functions," Transactions of the ASAE, Vol. 25, No. 2, 1982, pp. 396-400.

[16] E. Camecho, C. P. Lucena, J. R. Canas and M. Alcaide, "Model for Management and Control of Furrow Irrigation in Real-Time," Journal of Irrigation and Drainage Engineering, Vol. 123, No. 4, 1997, pp. 264-269. doi:10.1061/(ASCE)0733-9437(1997)123:4(264)

[17] K. L. Khatri and R. J. Smith, "Evaluation of Methods for Determining Infiltration Parameters from Irrigation Advance Data," Irrigation and Drainage, Vol. 54, No. 4, 2005, pp. 467-482. doi:10.1002/ird.198

[18] M. H. Gillies and R. J. Smith, "Infiltration Parameters from Surface Irrigation Advance and Runoff Data," Irrigation Science, Vol. 24, No. 1, 2005, pp. 25-35. doi:10.1007/s00271-005-0004-X

[19] P. Dalton, S. R. Raine and K. Broadfoot, "Best Management Practices for Maximising Whole Farm Irrigation Efficiency in the Australian Cotton Industry," Final Report to the Cotton Research and Development Corporation, National Centre for Engineering in Agriculture Report 179707/2, USQ, Toowoomba, 2001.

[20] W. R. Walker, "SIRMOD II: Surface Irrigation Simulation, Evaluation and Design," User's Guide and Technical Documentation, Utah State University, Logan, 2001.

[21] D. J. McClymont and R. J. Smith, "Infiltration Parameters from Optimization on Furrow Irrigation Advance Data,” Irrigation Science, Vol. 17, No. 1, 1996, pp. 15-22. doi:10.1007/s002710050017

[22] R. Rijsberman, "Water Scarcity: Fact or Fiction," Agricultural Water Management, Vol. 80, No. 1-3, 2006, pp. 5-22. doi:10.1016/j.agwat.2005.07.001

[23] H. Flessa, R. Ruser, P. Dorsh, T. Kamp, M. A. Jimenez, J. C. Munch and F. Beese, "Integrated Evaluation of Greenhouse Gas Emissions $\left(\mathrm{CO}_{2}, \mathrm{CH}_{4}, \mathrm{~N}_{2} \mathrm{O}\right)$ from Two Farming Systems in Southern Germany," Agriculture, Ecosystems \& Environment, Vol. 91, No. 1-3, 2002, pp. 175-189. doi:10.1016/S0167-8809(01)00234-1

[24] S. Kim and B. Dale, "Cumulative Energy and Global Warming Impact from the Production of Biomass for Bio-Based Products,” Journal of Industrial Ecology, Vol. 7, No. 3-4, 2003, pp. 147-162. doi:10.1162/108819803323059442

[25] T. M. Jackson, S. Khan and M. Hafeez, "A Comparative Analysis of Water Application and Energy Consumption at the Irrigated Field Level," Agricultural Water Management, Vol. 97, No. 10, 2010, pp. 1477-1485. doi:10.1016/j.agwat.2010.04.013

[26] M. Canakci, M. Topakci, I. Akinci and A. Ozmerzi, "Energy Use Pattern of Some Field Crops and Vegetable Production: Case Study for Antalya Region, Turkey,” Energy Conversion and Management, Vol. 46, No. 4, 2005, pp. 
655-666. doi:10.1016/j.enconman.2004.04.008

[27] S. A. Hatirli, B. Ozkan and C. Fert, "Energy Inputs and Crop Yield Relationship in Greenhouse Tomato Production,” Renewable Energy, Vol. 31, No. 4, 2006, pp. 427438. doi:10.1016/j.renene.2005.04.007
[28] B. Ozkan, H. Akcaoz and C. Fert, "Energy Input-Output Analysis in Turkish Agriculture," Renewable Energy, Vol. 29, No. 1, 2004, pp. 39-51.

doi:10.1016/S0960-1481(03)00135-6 